\title{
Study of iatrogenic bladder injury in vaginal hysterectomy: our experience
}

\author{
Pooja S. Singh*, Haresh U. Doshi
}

Department of Obstetrics and Gynecology, GCS Medical College and Research Hospital, Ahmedabad, Gujarat, India

Received: 11 February 2018

Accepted: 17 February 2018

\section{*Correspondence:}

Dr. Pooja S. Singh,

E-mail: drpsomesh03@yahoo.co.in

Copyright: (C) the author(s), publisher and licensee Medip Academy. This is an open-access article distributed under the terms of the Creative Commons Attribution Non-Commercial License, which permits unrestricted non-commercial use, distribution, and reproduction in any medium, provided the original work is properly cited.

\begin{abstract}
Background: This study was carried out to calculate the incidence of bladder injury detected during benign gynecologic vaginal hysterectomy. This investigation examined the clinical features of urologic complications during gynecologic surgery and outcome of their management.

Methods: It was a retrospective study done at Department of Gynecology, GCS medical college, Ahmedabad from year 2012-2016. All patients undergoing vaginal hysterectomy for benign diseases were included in the study. This study assessed the causative disease and surgical approach type, and treatment method of the bladder injury.

Results: Of these 237 patients who underwent vaginal hysterectomies, 3 (1.26\%) had bladder perforation. All the 3 cases of bladder injury underwent primary suturing during surgery without complications.

Conclusions: Bladder injury was the most common urological injury during obstetric and gynecologic surgery. Early diagnosis and urologic intervention is important for better outcomes.
\end{abstract}

Keywords: Bladder injury, Iatrogenic bladder, Vaginal hysterectomy

\section{INTRODUCTION}

The female genital and urinary tracts are anatomically closely related; therefore, the potential for injury to one must always be considered when operating on the other. Owing to improvements in gynecological and obstetric techniques that help to prevent urinary tract injury and an emphasis on immediate recognition and repair should any injury occur, long-term complications are less frequent nowadays. In India, the incidence of hysterectomy is about $4-6 \%$ of adult Indian women out of which $90 \%$ are performed for benign indications. ${ }^{1}$

The risk of damage increases when the normal anatomy is altered by primary pathologic factors or when it is insufficiently identified during intraoperative complications, such as severe bleeding or pelvic adhesions. $75 \%$ of urinary tract injuries are due to gynecologic surgery. ${ }^{2}$ Urinary tract injury complicates an estimated 0.2 to $1 \%$ of all gynecologic procedures and pelvic operations. ${ }^{3}$ To avoid injury to the urinary tract, the gynecologist must have an accurate understanding of pelvic anatomy, use a meticulous and methodical surgical technique, and maintain a constant high degree of vigilance. Recent reviews have suggested that whenever feasible Vaginal Hysterectomy should be preferred over Total Abdominal Hysterectomy and when Vaginal Hysterectomy is not possible, Total Laparoscopic Hysterectomy is the approach of choice.4 It is a general consensus that Vaginal Hysterectomy is considered the gold standard compared to Total Laparoscopic Hysterectomy. ${ }^{4}$

Present study was carried out calculate the incidence of bladder injury detected during benign gynecologic vaginal hysterectomy. This investigation examined the clinical features of urologic complications during gynecologic surgery and outcome of their management. 


\section{METHODS}

All patients who underwent vaginal hysterectomies for benign indications from 2012 through 2016 at Department of Gynecology, GCS Medical College and Hospital, Ahmedabad were included in the study and retrospectively analyzed. Exclusion criteria was other routes of hysterectomy which included abdominal hysterectomy, Total laparoscopic hysterectomy, LAVH, and radical hysterectomies.

Bladder complications were defined as laceration, perforation or rupture and leakage of contrast media out of the urinary tract found after surgery. Success of the repair was the criterion for successful treatment. Out of these, $3(1.26 \%)$ patients developed bladder injury and were enrolled in this study. All patients had a detailed history taken and a clinical examination performed.

Patients were followed-up in the outpatient clinic at 1, 3, and 6 months with detailed history, physical examination, complete urinalyses, and urine cultures at each visit. Patients with positive urine cultures received appropriate antibiotic therapy.

\section{RESULTS}

The total number of patients who were included in the study was 237, which had undergone vaginal hysterectomies for benign indications. Out of these, 3 $(1.26 \%)$ patients developed bladder injury. The bladder perforations and lacerations occured during the hysterectomy step of the surgery in all $3(100 \%)$ cases while opening vesico uterine pouch. All bladder injuries were recognized and treated during the primary operation. None of the patients treated by us had delayed complications like fistulas.

Table 1: Age distribution of women who underwent vaginal hysterectomies.

\begin{tabular}{|llll|}
\hline Age & $35-40$ yrs & $41-45$ yrs & $46-50$ yrs \\
$\begin{array}{l}\text { No. of } \\
\text { total cases }\end{array}$ & $56(23.6 \%)$ & $117(49.3 \%)$ & $64(27 \%)$ \\
\hline $\begin{array}{l}\text { Bladder } \\
\text { injury cases }\end{array}$ & 0 & $2(1.7 \%)$ & $1(1.56 \%)$ \\
\hline
\end{tabular}

This table shows that women undergoing vaginal surgery were maximally in the age range of $41-45$ yrs, accounting for $49.3 \%$ of cases, followed by $27 \%$ in the age range of 46-50 yrs age group. The bladder perforation is more common after 40 years of age. All the 3 such cases were above 40 years of age, the probable reason being waning oestrogen phase, which causes thinning of the tissues. The incidence of bladder injury was $1.7 \%$ in $41-45 \mathrm{yr}$ age group and $1.56 \%$ in $46-50$ yr age group.

Table 2: Etiology involved as an indication for undergoing vaginal hysterectomy.

\begin{tabular}{|lll|}
\hline Etiology & $\begin{array}{l}\text { Total no. } \\
\text { of cases }\end{array}$ & $\begin{array}{l}\text { No. of bladder } \\
\text { injury cases }\end{array}$ \\
\hline Adenomyosis & $78(32.9 \%)$ & $1(1.2 \%)$ \\
\hline Fibroid & $34(14.3 \%)$ & 0 \\
\hline $\begin{array}{l}\text { Pelvic inflammatory } \\
\text { disease }\end{array}$ & $44(18.5 \%)$ & $1(2.2 \%)$ \\
\hline Prolapse & $66(27.8 \%)$ & 0 \\
\hline $\begin{array}{l}\text { H/O previous one } \\
\text { caesarean section with }\end{array}$ & $15(6.3 \%)$ & $1(6.6 \%)$ \\
\hline AUB & & \\
\hline
\end{tabular}

Table 3: Type of bladder injury with 6 months follow up.

\begin{tabular}{|c|c|c|c|c|}
\hline Type of bladder injury & No. of cases & Immediate management & Post op. 3 weeks & Post op. 6 months \\
\hline Bladder perforation & $2(66.7 \%)$ & $\begin{array}{l}\text { Trans vaginal 2- layer } \\
\text { primary closure }\end{array}$ & $\begin{array}{l}\text { Normal bladder } \\
\text { function resumed }\end{array}$ & $\begin{array}{l}\text { Normal bladder } \\
\text { function }\end{array}$ \\
\hline Bladder laceration & $1(33.3 \%)$ & $\begin{array}{l}\text { Trans vaginal 2- layer } \\
\text { primary closure }\end{array}$ & $\begin{array}{l}\text { Normal bladder } \\
\text { function resumed }\end{array}$ & $\begin{array}{l}\text { Normal bladder } \\
\text { function }\end{array}$ \\
\hline Vesico vaginal fistula & 0 & None & None & None \\
\hline
\end{tabular}

The indications for pelvic surgery in the bladder injury patients were adenomyosis (1 case), history of previous cesarean section (1 case) and pelvic inflammatory disease ( 1 case). This shows that previous caesarean scar poses a threat while performing vaginal hysterectomy and incidence is high $(6.6 \%)$ in present study.

Also, pelvic infection masks the right planes for performing vaginal surgery, incidence being $2.2 \%$ in our study. In adenomyotic uterus, incidence of bladder injury was $1.2 \%$ in present study.
Of 3 patients of bladder injury, 2 patients $(66.7 \%)$ were of bladder perforations and 1 patient $(33.3 \%)$ of acute bladder laceration.

All bladder injuries were recognized and treated during the primary operation by vaginal route itself. All 3 $(100 \%)$ cases of bladder injury underwent combined transvaginal primary repair during surgery with a $100 \%$ success rate. Every patient received a urethral catheter, which was left indwelling for at least 14 to 21 days. 
Urethral catheters were removed only after confirming the absence of extravasation by cystogram. Bladder functions resumed after 3 weeks, and no late complication of vesico vaginal fistula was noted till 6 months follow up.

\section{DISCUSSION}

Urinary tract injury is the most common complication of pelvic surgery. The anatomic proximity of the reproductive and lower urinary system predisposes it to iatrogenic injuries. Its incidence is reported to be from 0.5 to $1.5 \%$, and bladder injury is more common than ureter injury.$^{5-7}$ Most bladder injuries, but only one third of all ureter injuries, are identified during surgery.

Intraoperatively recognized injuries are usually more easily repaired at the time without the need for a second surgical intervention. In this situation, surgeons were able to find the borders of viable tissues more readily and were able to avoid unnecessary excision. As a result, the rate of bleeding complications was lower and suture tension was reduced. ${ }^{8}$

In present study, the incidence of iatrogenic bladder injury during vaginal hysterectomies was $1.26 \%$ and the most common indication for vaginal hysterectomy was adenomyosis $(32.9 \%$ cases $)$ followed by prolapse $(27.8 \%)$ and PID $(18.5 \%)$. These injuries were detected intra operatively and managed effectively.

With regard to mode of hysterectomy, vaginal hysterectomy is reported to have a lower incidence of ureteral injury when compared with abdominal hysterectomy $(0.9 \%$ vs $1.7 \%$, although the differences did not reach statistical significance).$^{9,10}$ Multiple cesarean deliveries are also associated with an increased risk of pelvic adhesive disease, and difficulty with bladder dissection during subsequent gynecologic surgery can be expected. ${ }^{11}$ The bladder dome, adhered to the lower uterine segment, requires meticulous dissection to avoid injury to the bladder. This suggests that the bladder is the most common site of urinary tract injury during pelvic surgery.

The observed high incidence of bladder injury may be due to the fact that such injuries are easier to detect than injuries occurring at other sites. They are easily recognized and treated during the primary operation without important sequelae. The standard repair is a twolayer closure including the mucosa with absorbable suture material. On the other hand, extraperitoneal injuries are often treated conservatively by decompression of the bladder with a Foley catheter and observation.

\section{CONCLUSION}

Bladder injury occurred very frequently as opposed to ureteral injury. The most common form of injury is intra- operative detection of urinary bladder laceration and it is treated by primary bladder repair. ${ }^{12}$ When a urologic complication develops, early diagnosis and early urologic intervention is necessary to prevent the occurrence of delayed urologic complications.

Minimizing the risk of intraoperative injury requires maintaining visual identification of the ureters and bladder in relation to the operative target. This also allows early recognition of injury, should it occur. Confirmatory measures for further reorientation include palpation of the ureters and bladder, bladder back-filling, administration of intravenous (IV) dye, cystoscopy, and retrograde pyelography.

\section{Funding: No funding sources}

Conflict of interest: None declared

Ethical approval: The study was approved by the Institutional Ethics Committee

\section{REFERENCES}

1. Singh AJ, Arora AK. Effect of uterine prolapse on the lines of rural North Indian women. Singapore J Obstet Gynecol. 2003;34:52-8.

2. Thompson JD. Operative injuries to the ureter: prevention, recognition, and management. In: Rock JA, Thompson JD, editors. TeLinde's operative gynecology. $\quad 8^{\text {th }}$ ed. Philadelphia: Lippincott Williams and Wilkins;1997:1135-117.

3. Gilmour DT, Dwyer PL, Carey MP. Lower urinary tract injury during gynecologic surgery and its detection by intraoperative cystoscopy. Obstet Gynecol. 1999;94(5 Pt 2):883-9.

4. Aarts JWM, Nieboer TE, Johnson N, Tavender E, Garry R, Mol BJ et al. Surgical approach to hysterectomy for benign gynecological disease. .2015

5. Aronson MP, Bose TM. Urinary tract injury in pelvic surgery. Clin Obstet Gynecol. 2002;45:428-38.

6. Frankman EA, Wang L, Bunker CH, Lowder JL. Lower urinary tract injury in women in the United States, 1979-2006. Am J Obstet Gynecol. 2010;202:495e1-495e5.

7. Ozdemir E, Ozturk U, Celen S, Sucak A, Gunel M, Guney G, et al. Urinary complications of gynecologic surgery: iatrogenic urinary tract system injuries in obstetrics and gynecology operations. Clin Exp Obstet Gynecol. 2011;38:217-20.

8. Moriel EZ, Meirow D, Zilberman M, Farkas A. Experience with the immediate treatment of iatrogenic bladder injuries and the repair of complex vesico-vaginal fistulae by the transvesical approach. Arch Gynecol Obstet. 1993;253:127-30.

9. Ibeanu OA, Chesson RR, Echols KT, Nieves M, Busangu F, Nolan TE. Urinary tract injury during hysterectomy based on universal cystoscopy. Obstet Gynecol. 2009;113(1):6-10.

10. Vakili B, Chesson RR, Kyle BL, et al. The incidence of urinary tract injury during hysterectomy: a 
prospective analysis based on universal cystoscopy. Am J Obstet Gynecol. 2005;192(5):1599-604.

11. Tulandi T, Agdi M, Zarei A, Miner L, Sikirica V. Adhesion development and morbidity after repeat cesarean delivery. Am J Obstet Gynecol. 2009;201(1):56.e1-56.e6.
12. Lee JS, Choe JH, Lee HS, Seo JT. Urologic complications following obstetric and gynecologic surgery. Korean J Urol. 2012;53:795-9.

Cite this article as: Singh PS, Doshi HU. Study of iatrogenic bladder injury in vaginal hysterectomy: our experience. Int J Reprod Contracept Obstet Gynecol 2018;7:903-6. 